\title{
Insufficient lymph node assessment in gastric adenocarcinoma
}

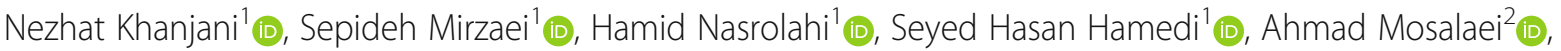 \\ Shapour Omidvari ${ }^{3}$ (D) Niloofar Ahmadloo ${ }^{1}$ (D), Mansour Ansari ${ }^{3}$ (D), Fatemeh Sobhani $i^{1}$ (i) and \\ Mohammad Mohammadianpanah ${ }^{4^{*}}$ (D)
}

\begin{abstract}
Background: This study aimed to investigate the sufficient $(\geq 16)$ lymph node assessment in 449 patients with gastric adenocarcinoma and literature review.

Methods: Four hundred and forty-nine patients with pathologically confirmed locoregional invasive gastric adenocarcinoma from 2004 to 2013 were included. A standard surgical resection was performed for all the patients with $(n=16)$ or without $(n=433)$ neoadjuvant treatment.

Results: In this study, 301 men and 148 women with a median age of 58 (range 21-88) years were included. The median total numbers of examined lymph nodes were 9 (range $0-55$ ). Ninety-five patients (21.2\%) had adequate ( $\geq 16$ ) lymph node examination, and 70 patients (15.6\%) had no examined lymph nodes. In univariate analysis, total or near total gastrectomy $(P<0.001)$, advanced node stage $(P<0.001)$, primary tumor size $>6 \mathrm{~cm}(P<0.001)$, and the presence of perineural invasion $(P=0.039)$ were associated with more average number of examined lymph nodes. On multivariate analysis, node stage $(P<0.001)$ and type of surgery $(P=0.008)$ were independent predictive factors.

Conclusion: In this study, approximately one in five patients with gastric adenocarcinoma had sufficient lymph node assessment. More studies are suggested for identifying a true inadequate lymph node dissection from insufficient lymph node assessment.
\end{abstract}

Keywords: Gastric cancer, Adenocarcinoma, Stomach, Lymph node dissection, Surgery

\section{Highlights}

1. In this study, the median total numbers of examined lymph nodes were 9 (range 0-55).

2. Ninety-five patients $(21.2 \%)$ had adequate $(\geq 16)$ lymph nodes examination, and 70 patients $(15.6 \%)$ had no examined lymph nodes.

3. Total or near total gastrectomy, advanced primary tumor and node stage, tumor size $>6 \mathrm{~cm}$, and the presence of perineural invasion were associated with more median number of examined lymph nodes.

4. Advanced node stage and total or near total gastrectomy were independent predictive factors for adequate lymph node assessment.

\footnotetext{
* Correspondence: mohpanah@gmail.com

${ }^{4}$ Colorectal Research Center, Shiraz University of Medical Sciences, Shiraz 71936, Iran

Full list of author information is available at the end of the article
}

\section{Background}

Gastric cancer remains the fourth most frequent cancer and the second leading cause of cancer death worldwide. Despite a decline in incidence of gastric cancer in the western countries, it is still a major malignant disease [1].

In most countries, this malignancy present at late stage due to undefined risk factors and non-specific symptoms. Surgery is the mainstay of curative treatment of gastric cancer. In gastric cancer surgery, no residual tumor (R0) resection is an ultimate goal; however, there has been strong argue regarding the degree of lymph node (LN) dissection. This argument involves sufficient surgical and pathological staging and satisfactory adjuvant therapy. Generally, limited LN dissection (D1) involves perigastric LNs surrounded by $3 \mathrm{~cm}$ from the primary tumor, extended LN dissection (D2) extends the dissection outside D1 to include LNs surrounding the hepatic and splenic arteries, and superextended LN 
dissection (D3) further includes LNs in the retropancreatic, paraaortic, and the root of the mesocolon LNs. Further LN dissection such as D2 resection may potentially offer more precise pathologic staging, enhanced regional tumor control, and potential survival improvement. All these issues, however, need to be proven, because the results of randomized clinical trials have failed to confirm a clear disease control and survival benefit to date [2].

In the fifth edition of the American Joint Committee on Cancer (AJCC) Tumor, Node, Metastasis (TNM) classification for gastric cancer, the number of positive nodes was considered as the base of LN classification. This classification showed superiority over the prior classification system in terms of LN stage as a prognostic factor. However, as it is expected, the more LN evaluated, nodal metastases detection is more likely. The number of nodal examined depends not only on the extent of LN dissection, but also on the lymph node retrieval. Therefore, when the number of examined LNs is insufficient for diagnosis, the nodal stage may be underestimated, which is so-called stage migration [3].

The 7th edition of the AJCC staging manual (2010) revised the nodal classification system such that $\mathrm{N} 1=1-2$ positive LNs; N2 $=3-6$ positive $\mathrm{LNs}$; N3a $=7-15$ positive LNs; and N3b > 15 LNs. As such, the AJCC now recommends that at least $16 \mathrm{LNs}$ be assessed per patient. The staging changes attempt to minimize the impact of surgical dissection on gastric cancer staging and to improve the prognostic ability of $\mathrm{N}$-staging compared to that in the 5th/6th editions. Unfortunately, despite the changes to simplify staging, the number of LNs assessed in each gastric cancer case varies, and in many cases, the number reported per specimen is less than current recommendations [3].

The present study aimed to investigate the sufficient ( $\geq 16)$ lymph node evaluation in patients with resected gastric adenocarcinoma, and review of the literature.

\section{Methods}

In this retrospective study, a chart review was performed on 449 patients with resected locoregional invasive gastric adenocarcinoma who were treated and followed up at a referral academic hospital, between 2004 and 2013. A minimum sample size required for the study was calculated based on the value of standard deviation of the mean total number of assessed LN $(\mathrm{SD}=11.02)$ in previous study by Zhao [4]. Accordingly, a minimum of 117 patients were estimated for a precision of $2 \%$. Exclusion criteria in this study were in situ or metastatic tumor, pathologies other than adenocarcinoma, and unresectable or inoperable gastric cancer. Additionally, patients who had been treated with palliative surgery were excluded. The patients' cancers were reclassified according to the 8th edition of the AJCC. Four hundred and thirtythree patients underwent primary surgery, and the remaining 16 cases received neoadjuvant chemotherapy and/or chemoradiation before curative surgical resection. Initial investigation involved a history taking and physical examination, upper GI endoscopy, laboratory test, and chest, abdominal, and pelvic computed tomography (CT) scans.

All statistical analysis was performed using IBM SPSS 22. The median, as well as the percentage of patients with sufficient $(\geq 16)$ and insufficient $(<16)$ evaluated LN, was initially calculated. All potential clinical (age, sex, tumor location, type of surgery) and pathological (histologic form, tumor stage, node stage, tumor grade, lymphovascular invasion, perineural invasion, tumor size, surgical margin status, and the total and adequate assessed LNs) variables were analyzed. The outcome variable were measured based on the median and adequate $(\geq 16)$ total number of assessed lymph node. The impact of all potential variables on the median and adequate $(\geq 16)$ total number of assessed lymph node was analyzed using non-parametric (Mann-Whitney $U$ test and Kruskal-Wallis test) tests respectively. Initially, a univariate analysis for the dependent variable adequate $(\geq 16)$ LN assessment was performed. In the final step, all significant factors were included in a stepwise multivariate logistic analysis. All statistical tests were twoended, and $p$ values less than 0.05 were considered statistically significant.

\section{Results}

In this study, 301 men and 148 women with a median age of 60 (range 21-88) years were included. Two hundred and twenty-one patients were less than 60 years old, and 228 patients were older than or equal to 60 years old. The distribution of histologic form $(P<0.001)$, tumor grade $(P=0.027)$, and tumor size $(P=0.016)$ was significantly different among tumor location (Table 1). Accordingly, diffuse gastric involvement tended to be presented with larger tumor size, to have higher rate of poorly differentiated tumor and diffuse histologic type. The median total numbers of evaluated lymph nodes were 9 (range 0 $55)$. Only 95 patients (21.2\%) had equal or more than 16 lymph nodes evaluation, and 70 patients (15.6\%) had no any lymph nodes for evaluation. Relative distribution of total lymph node evaluation has been illustrated in Fig. 1. Two hundred and sixty-two patients $(58.3 \%)$ were node positive. Association of potential variables on median total lymph node count has been illustrated in Table 2. Additionally, an association was found between positive node and lymphatic vascular invasion $(P<0.001)$, the presence of perineural invasion $(P<0.001)$, and advanced $\mathrm{T}$ stages 
Table 1 Patient and tumor characteristics by tumor location

\begin{tabular}{|c|c|c|c|c|c|}
\hline \multirow[t]{2}{*}{ Characteristics } & \multicolumn{4}{|c|}{ Tumor location (\%) } & \multirow[t]{2}{*}{$P$ value } \\
\hline & Proximal & Distal & Diffuse & Total & \\
\hline Gender & & & & & 0.298 \\
\hline Male & $124(42.8)$ & $137(47.2)$ & $29(10)$ & $290(100)$ & \\
\hline Female & $50(35.0)$ & $77(53.8)$ & $16(11.2)$ & $143(100)$ & \\
\hline Age & & & & & 0.463 \\
\hline Median (range) & $60(27-84)$ & $58(21-82)$ & $59(26-84)$ & $60(21-88)$ & \\
\hline Histologic form & & & & & $<0.001$ \\
\hline Diffuse type & $68(39.8)$ & $73(42.7)$ & $30(17.5)$ & $171(100)$ & \\
\hline Intestinal type & $96(41.9)$ & $122(53.3)$ & $11(4.8)$ & $229(100)$ & \\
\hline T stage & & & & & 0.250 \\
\hline 1 & $4(21.1)$ & $13(68.4)$ & $2(10.5)$ & $19(100)$ & \\
\hline 2 & $21(44.7)$ & $25(53.2)$ & $1(2.1)$ & $47(100)$ & \\
\hline 3 & $103(40.9)$ & $122(48.4)$ & $27(10.7)$ & $252(100)$ & \\
\hline 4 & $32(36.8)$ & $43(49.4)$ & $12(13.8)$ & $87(100)$ & \\
\hline $\mathrm{N}$ stage & & & & & 0.641 \\
\hline No & $49(45.8)$ & $47(43.9)$ & $11(10.3)$ & $107(100)$ & \\
\hline N1 & $32(45.0)$ & $30(42.3)$ & $9(12.7)$ & $71(100)$ & \\
\hline N2 & $36(36.4)$ & $54(54.5)$ & $9(9.1)$ & $99(100)$ & \\
\hline N3 & $37(41.1)$ & $40(44.5)$ & $13(14.4)$ & $90(100)$ & \\
\hline Tumor grade & & & & & 0.027 \\
\hline Well differentiated & $42(47.7)$ & $43(48.9)$ & $3(3.4)$ & $88(100)$ & \\
\hline Moderately differentiated & $59(41.6)$ & $74(52.1)$ & $9(6.3)$ & $142(100)$ & \\
\hline Poorly differentiated & $69(36.9)$ & $92(49.2)$ & $26(13.9)$ & $187(100)$ & \\
\hline Lymphatic-vascular invasion & & & & & 0.055 \\
\hline Negative & $52(46.4)$ & $54(48.2)$ & $6(5.4)$ & $112(100)$ & \\
\hline Positive & $110(37.0)$ & $150(50.5)$ & $37(12.5)$ & $297(100)$ & \\
\hline Perineural invasion & & & & & 0.388 \\
\hline Negative & $61(43.6)$ & $67(47.8)$ & $12(8.6)$ & $140(100)$ & \\
\hline Positive & $100(37.3)$ & $137(51.1)$ & $31(11.6)$ & $268(100)$ & \\
\hline Tumor size & & & & & 0.016 \\
\hline$\leq 6 \mathrm{~cm}$ & $101(38.4)$ & $142(54.0)$ & $20(7.6)$ & $263(100)$ & \\
\hline$>6 \mathrm{~cm}$ & $56(45.2)$ & $50(40.3)$ & $18(14.5)$ & $124(100)$ & \\
\hline Surgical margin status & & & & & 0.292 \\
\hline Free & $113(38.4)$ & $152(51.7)$ & $29(9.9)$ & $295(100)$ & \\
\hline Involved & $47(44.8)$ & $45(42.8)$ & $13(12.4)$ & $105(100)$ & \\
\hline Total LN examined & & & & & 0.099 \\
\hline Median (range) & $9(0-48)$ & $7(0-55)$ & $11(0-45)$ & $8(0-55)$ & \\
\hline Adequate LN examined & & & & & 0.092 \\
\hline Inadequate (< 16 LNs) & $131(38.5)$ & $177(52.1)$ & $32(9.4)$ & $340(100)$ & \\
\hline Adequate ( $\geq 16$ LNs) & $43(46.2)$ & $37(39.8)$ & $13(14.0)$ & $93(100)$ & \\
\hline
\end{tabular}

$L N$ lymph node

$(P<0.001)$. In univariate analysis, type of gastrectomy $(P<0.001$, node stage $(P<0.001)$, primary tumor size $(P<0.001)$, and perineural invasion $(P=0.039)$ were significant variables (Table 3 ). In multivariate analysis using logistic regression method, N3 node stage $(P<$ $0.001, \quad \mathrm{OR}=5.907, \quad \mathrm{CI}=3.462-10.081)$ and total or 


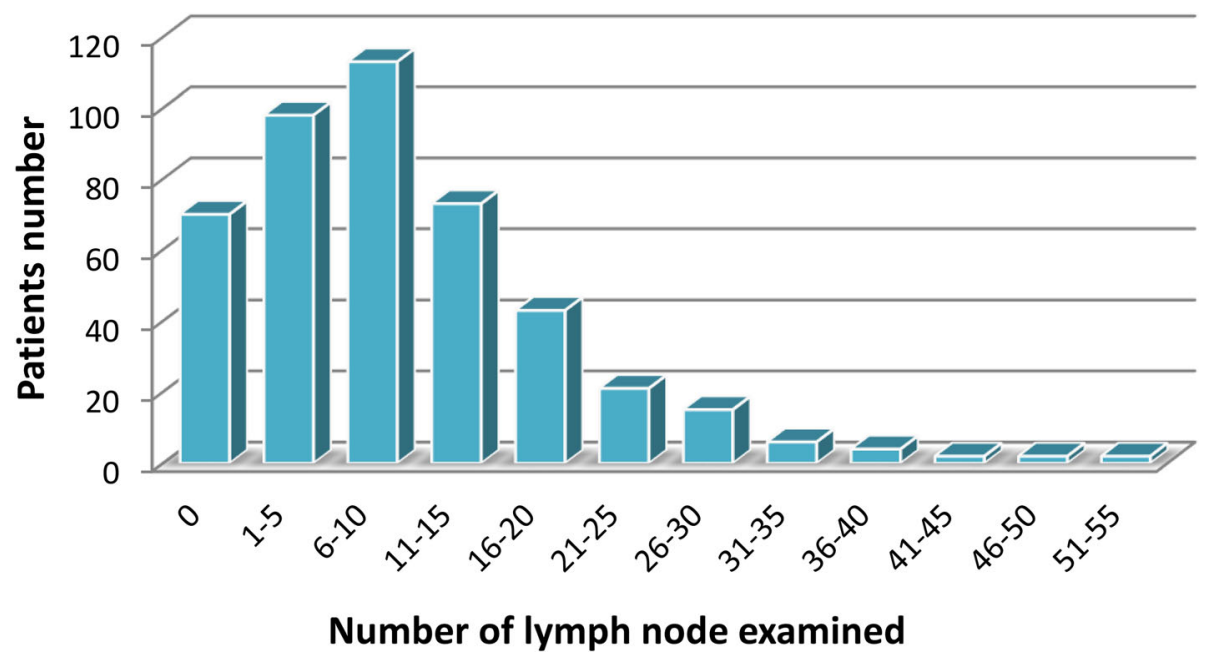

Fig. 1 Relative distribution of total lymph node evaluation in 449 patients with resected gastric cancer

near total gastrectomy $(P=0.008, \mathrm{OR}=2.146, \mathrm{CI}=$ $1.221-3.772$ ) were independent variables (Table 4).

\section{Discussion}

Gastric cancer remains a major health problem not only in developing, but also in developed countries. Surgical treatment including complete resection of primary tumor and regional LN dissection plays an essential role in treating these patients. Theoretically, an insufficient LN dissection increases the risk of potential microscopic and gross residual tumor cell, higher rate of recurrent disease, and poorer prognosis [5]. It is believed that by increasing the number of surgically dissected and pathologically harvested LNs, surgical and pathological staging will be more accurate. Subsequently, this can potentially enhance locoregional tumor control and improves oncologic outcomes following gastric cancer surgery. Accordingly, a minimum number of 16-LN evaluation was recommended to achieve precise staging [6]. Despite many years after changing in gastric cancer staging, only $33 \%$ of patients had an adequate lymph node assessment.

The occurrence of gastric cancer in patients younger than 40 years old is uncommon; however, after which, its incidence increases progressively. In the current study, the patients with a median age of 60 years old were younger than that of the results of previous reports in which the average median age of 27,214 patients in 15 report series was 65.5 (range 54-71) years old [1, 4, 618] (Table 5). During recent decades, the frequency of primary tumor location has been changed in favor of proximal gastric cancers. At present, proximal gastric cancers including gastroesophageal junction lesions are diagnosed more frequently than in the past. Nevertheless, most gastric cancers still originate from distal stomach. The largest percentage of gastric cancers still arise within the antrum or distal stomach [19]. In this study, most of the lesions were in the distal of stomach $(50.5 \%)$. In major reported series, the average total number of lymph node evaluated was 27.7 (range 8.4-35.3) for 7643 patients in 8 studies $[4,6,8-12,20]$. In this research, the average total number of evaluated lymph node was 11.1. Furthermore, in the current study, 58\% of all patients had stage III which was higher than that of major reported series in which this value was $31.2 \%$ (range $15.5 \%-64 \%$ ) for 22,994 patients in 10 series [2, 7$10,13-16,18,20]$. In gastric cancer, insufficient lymph node assessment is a common finding in the literature. By analyzing data of 15 series including 27,942 patients, 52.2\% (range 17.6-94.2\%) of all patients had adequate ( $\geq 16)$ lymph node evaluation $[1,2,4,6-9,13-18,21$, 22] (Table 5). In the present study, only $21.2 \%$ of patients had a sufficient lymph node assessment which seems to be much lower than that of average value in the literature.

The cause of insufficient lymph node assessment is multifactorial. A cooperation between the surgeon for doing optimal lymph node dissection and pathologist for doing sufficient lymph node assessment is required [23]. However, according to multiple studies, a variety of factors can affect both parties, including ethic background such as body mass index (that affect the surgeon's ability to perform an adequate lymphadenectomy), age (younger patients are more likely to have an adequate LN assessment), and region in which the surgery is performed [21]. In this study, age and sex have no significant relation with examined lymph nodes. Regarding the tumor and treatment factors, the average number of evaluated lymph node was associated significantly with primary site, node stage, tumor size, perineural invasion, type of surgery, and neoadjuvant treatment. Higher lymph node 
Table 2 Association of potential variables on median total lymph node count in 449 patients with resected gastric adenocarcinoma

\begin{tabular}{|c|c|c|c|}
\hline Variables & $\begin{array}{l}\text { Patients' } \\
\text { no. }\end{array}$ & $\begin{array}{l}\text { Median total LNs } \\
\text { examined (Q1, Q3) }\end{array}$ & $P$ value \\
\hline \multicolumn{4}{|l|}{ Patients' sex } \\
\hline Male & 301 & $8(3,14)$ & \\
\hline Female & 148 & $8(3,13)$ & 0.964 \\
\hline \multicolumn{4}{|l|}{ Patients' age } \\
\hline$<60$ years & 221 & $8(3,12)$ & \\
\hline$\geq 60$ years & 228 & $8(3,15)$ & 0.387 \\
\hline \multicolumn{4}{|l|}{ Primary tumor site } \\
\hline Diffuse & 45 & $11(5,18)$ & \\
\hline Non diffuse & 388 & $7(2,12)$ & 0.298 \\
\hline \multicolumn{4}{|l|}{ Type of gastric surgery } \\
\hline $\begin{array}{l}\text { Total or near total } \\
\text { gastrectomy }\end{array}$ & 246 & $10(5,17)$ & \\
\hline $\begin{array}{l}\text { Partial or subtotal } \\
\text { gastrectomy }\end{array}$ & 167 & $7(3,11)$ & 0.001 \\
\hline \multicolumn{4}{|l|}{ Primary tumor stage } \\
\hline $\mathrm{T} 1-2$ & 69 & $7(4,11)$ & \\
\hline T3-4 & 348 & $9(4,15)$ & 0.024 \\
\hline \multicolumn{4}{|l|}{ Node stage } \\
\hline No-2 & 286 & $7(4,12)$ & \\
\hline N3 & 92 & $17(11,25)$ & $<0.001$ \\
\hline \multicolumn{4}{|l|}{ Tumor size } \\
\hline$\leq 6 \mathrm{~cm}$ & 263 & $7.5(4,12)$ & \\
\hline$>6 \mathrm{~cm}$ & 124 & $12(6,19)$ & $<0.001$ \\
\hline \multicolumn{4}{|c|}{ Neoadjuvant treatment } \\
\hline Not received & 433 & $8(4,14)$ & \\
\hline Received & 16 & $5(0,6)$ & 0.132 \\
\hline \multicolumn{4}{|l|}{ Surgical margin status } \\
\hline Free & 295 & $8(4,14)$ & \\
\hline Involved & 105 & $9(5,16)$ & 0.445 \\
\hline \multicolumn{4}{|l|}{ Tumor grade } \\
\hline Grades I-II & 234 & $8(3,14)$ & \\
\hline Grade III & 198 & $8(4,13)$ & 0.567 \\
\hline \multicolumn{4}{|c|}{ Lymphatic-vascular invasion } \\
\hline Negative & 112 & $8(4,13)$ & \\
\hline Positive & 297 & $8(4,14)$ & 0.590 \\
\hline \multicolumn{4}{|l|}{ Perineural invasion } \\
\hline Negative & 140 & $7(4,12)$ & \\
\hline Positive & 268 & $9(4,16)$ & 0.039 \\
\hline \multicolumn{4}{|l|}{ Histologic form } \\
\hline Diffuse type & 171 & $8(4,15)$ & \\
\hline Intestinal type & 229 & $8(3,13)$ & 0.372 \\
\hline
\end{tabular}

Table 3 Univariate analyses for the dependent variable, adequate $(\geq 16)$ LN assessment in 449 patients with resected gastric adenocarcinoma

\begin{tabular}{|c|c|c|c|}
\hline Variables & Patients' no. & $\begin{array}{l}\text { No. of adequate }(\geq 16) \mathrm{LN} \\
\text { assessment }(\%)\end{array}$ & $P$ value \\
\hline \multicolumn{4}{|l|}{ Patients' sex } \\
\hline Male & 301 & $64(21.3)$ & \\
\hline Female & 148 & $31(20.9)$ & 0.938 \\
\hline \multicolumn{4}{|l|}{ Patients' age } \\
\hline$<60$ years & 221 & $51(21.3)$ & \\
\hline$\geq 60$ years & 228 & $44(19.3)$ & 0.327 \\
\hline \multicolumn{4}{|l|}{ Primary tumor site } \\
\hline Diffuse & 45 & $13(28.9)$ & \\
\hline Non diffuse & 388 & $80(20.6)$ & 0.201 \\
\hline \multicolumn{4}{|l|}{ Type of gastric surgery } \\
\hline $\begin{array}{l}\text { Total or near total } \\
\text { gastrectomy }\end{array}$ & 246 & $72(21.9)$ & \\
\hline $\begin{array}{l}\text { Partial or subtotal } \\
\text { gastrectomy }\end{array}$ & 167 & $23(13.8)$ & $<0.001$ \\
\hline \multicolumn{4}{|l|}{ Primary tumor stage } \\
\hline $\mathrm{T} 1-2$ & 69 & $12(17.4)$ & \\
\hline T3-4 & 348 & $83(23.9)$ & 0.243 \\
\hline
\end{tabular}

Node stage

No-2 $286 \quad 43(15.0)$

N3 $92-51(55.4)$

Tumor size

$\begin{array}{lll}\leq 6 \mathrm{~cm} & 263 & 48(17.3) \\ >6 \mathrm{~cm} & 124 & 45(35.2)\end{array}$

Neoadjuvant treatment

$\begin{array}{llll}\text { Not received } & 433 & 94(22.0) & \\ \text { Received } & 16 & 1(6.3) & 0.087\end{array}$

Surgical margin status

Free $\quad 305 \quad 66(21.6)$

Involved $\quad 107 \quad 27(25.2)$

0.444

Tumor grade

Grades I-II $\quad 234 \quad 49(20.9)$

Grade III $\quad 198 \quad 46$ (23.2)

0.567

Lymphatic-vascular invasion

Negative $\quad 117 \quad 24(20.5)$

$\begin{array}{lll}\text { Positive } & 305 & 70(23.0)\end{array}$

0.590

Perineural invasion

$\begin{array}{lll}\text { Negative } & 145 & 24(16.6) \\ \text { Positive } & 276 & 70(25.4)\end{array}$

$70(25.4)$

0.039

Histologic form

$\begin{array}{lll}\text { Diffuse type } & 182 & 44(24.2) \\ \text { Intestinal type } & 234 & 48(20.5)\end{array}$

0.372

LN lymph node 
Table 4 Independent variables associated with adequate $(\geq 16)$ lymph node assessment in resected gastric adenocarcinoma

\begin{tabular}{lccc}
\hline Variables & $P$ value & Odds ratio & $\mathrm{Cl}(95 \%)$ \\
\hline Type of gastric surgery & & & \\
Partial or subtotal gastrectomy & & & \\
Total or near total gastrectomy & 0.008 & 2.146 & $1.221-3.772$ \\
Node stage & & & \\
N0-2 & & & \\
N3 & $<0.001$ & 5.907 & $3.462-10.081$ \\
Tumor size & & & \\
$\leq 6$ cm & & & \\
$>6$ cm & 0.120 & 1.535 & $0.894-2.635$ \\
Perineural invasion & & & \\
$\quad$ Negative & & & \\
Positive & 0.674 & 1.138 & $0.624-2.075$ \\
\hline
\end{tabular}

Cl confidence interval

examined was yield in total or near total gastrectomy, stage N3, tumor size $>6 \mathrm{~cm}$, and presence of perineural invasion. The type of gastric surgery and extent of $\mathrm{LN}$ dissection remains an important factor in the adequacy of lymph node sampling and survival outcomes. Therefore, the surgeon can be considered as one of the most independent predictive factor in gastric cancer for achieving adequate lymph node sampling, R0 resection and locoregional disease control [24]. In this study, total gastrectomy was associated with more average number of examined lymph nodes compared to those with subtotal gastrectomy. In the current study, due to large number of surgeons, pathologists, and hospitals, to investigate any association between adequate lymph node assessment and the surgeon, pathologists, and hospitals was not possible. Many factors affected the probability of sufficient LN assessment in the patients. In the final multivariable Cox model, factors of age, sex, year of diagnosis, type of surgery, tumor stage, and tumor grade remained significant predictors for adequate lymph node assessment [2]. There are conflicting reports regarding the impact of different variables on examined lymph nodes. Gholami et al. analyzed 742 patients who underwent gastrectomy for gastric adenocarcinoma. They found patients with more advanced $\mathrm{T}$ and $\mathrm{N}$ stage, younger age, and D2 lymphadenectomy tended to have adequate LN assessment. The rest of the variables including resection margin status, type of gastrectomy, grade of tumor, and sex were not related to obtain adequate lymph node dissection [18].

Biffi et al. demonstrated no association between the factors of sex, age, type of adenocarcinoma, T stage, and grade of the tumor and the number of dissected lymph nodes. There were dissected lymph nodes $>15$ only in patients that did not receive neoadjuvant treatment [1].

Zhao et al. reported that no relation was noted between age, tumor site, or tumor grade and number of

Table 5 The status of lymph nodes assessment in resected gastric adenocarcinoma in major reported series in the literature

\begin{tabular}{|c|c|c|c|c|c|c|c|}
\hline Authors & No. of patients & Stage & Median age & Mean TLN & Median TLNE & Mean $\%$ of stage III & $\%$ of ALNE \\
\hline Biffi et al. [1] & 114 & $|-| \mid$ & 63 & NR & 22 & NR & 78.9 \\
\hline Bouvier et al. [6] & 749 & $|-|||$ & 68 & 8.4 & $N R$ & $N R$ & 17.6 \\
\hline Bruno et al. [10] & 367 & I-IV & 67 & 17.4 & 15 & 32.6 & NR \\
\hline Chen et al. [7] & 1101 & I-IV & 58 & NR & NR & 35.8 & 68.5 \\
\hline Coburn et al. [14] & 10,807 & I-IV & 70 & NR & 9 & 27.5 & 29 \\
\hline Deng et al. [12] & 196 & $\|-I V$ & 69 & 15.7 & NR & NR & 75 \\
\hline Gholami et al. [18] & 742 & $|-|||$ & 65 & NR & NR & 15.5 & 65 \\
\hline Giuliani et al. [11] & 154 & $|-|||$ & 65 & 22.6 & NR & NR & NR \\
\hline Huang et al. [8] & 634 & I-IV & $N R$ & NR & $N R$ & 44.2 & 83.1 \\
\hline Huang et al. [22] & 236 & I-IV & 58 & 23.8 & 23 & NR & 84.7 \\
\hline Ichikura et al. [9] & 925 & I-IV & 57 & 32 & 30 & 16.4 & 77 \\
\hline Lee et al. [13] & 4789 & I-IV & 54 & 31.9 & 30 & 28 & 94.2 \\
\hline Marubini et al. [2] & 615 & I-IV & NR & NR & NR & 39.8 & 73.2 \\
\hline Schwarz and Smith [15] & 1377 & $\|-\| \|$ & 68 & NR & 17 & 48.4 & 74.7 \\
\hline Shen et al. [16] & 1637 & I-IV & 65 & NR & 19 & 54.7 & 81.4 \\
\hline Smith et al. [21] & 3793 & $|-| \mid$ & 71 & NR & 8 & NR & 25 \\
\hline Zhao et al. [4] & 227 & । & 57 & 18.51 & NR & NR & 55.5 \\
\hline Present study & 449 & $|-|||$ & 60 & 11.1 & 9 & 58.3 & 21.2 \\
\hline Total & 28,912 & I-V & 65.4 & 27.7 & 15.1 & 31.7 & 51.7 \\
\hline
\end{tabular}


dissected lymph nodes. More women were in the $\leq 15$ LN group than in those with $>15$ LN [4].

Huang et al. was performed the study in 634 patients with gastric cancer. In their study, the clinicopathological characteristics of patients like gender, age, tumor size, tumor location, grade of tumor, and $\mathrm{T}$ stage did not influence the number of examined lymph nodes [19]. Many reports showed a major role for surgical volume and experience of the surgeons and pathologist on lymph node retrieval in gastric cancer. High volume of surgery such as total and near total gastrectomy provides more removal and examination of regional LNs. In addition, in cases with higher $\mathrm{T}$ stage, gross LN involvement is more frequent which facilitates more $\mathrm{LN}$ detection and dissection by the surgeon and more LN retrieval by pathologist. Likewise, neoadjuvant therapies such as chemotherapy and chemoradiation can potentially shrinkage and disappear gross involved LNs and subsequently decrease the number of LN detection, dissection, and examination in gastric cancer. Conversely, in patients with early-stage gastric cancer, low-volume limited surgery may be associated with inadequate $\mathrm{LN}$ staging in these patients $[17,25]$.

In Iran, many factors including the paucity of experienced surgical oncologist and pathologist and particularly infrequent extended LN dissection may contribute to insufficient LN assessment in gastric cancer.

The limitation of the current study were retrospective chart review of the patients' medical records, unknown operative details regarding surgical approach and LN location, non-uniform pathologic reports, and relatively small sample size of a single institution data based.

\section{Conclusion}

This study indicates that only one fifth of patients with gastric adenocarcinoma underwent sufficient lymph nodes assessment in Shiraz, Iran. As well, in this research, about 15\% of the patients had no lymph nodes for assessment. Multicenter studies with larger sample size are suggested to confirm these results and to identify a true insufficient lymph node dissection from insufficient lymph node detection.

\section{Abbreviations}

AJCC: American Joint Committee on Cancer; CT: Computed tomography; LN: Lymph node; N stage: Node stage; SD: Standard deviation; T stage: Tumor stage; TNM: Tumor, Node, Metastasis

\section{Acknowledgements}

This study was approved and supported by Shiraz University of Medical Sciences (research project number 98-01-01-19714). This manuscript is part of a thesis by Fatemeh Sobhani.

\section{Authors' contributions}

$\mathrm{NK}$ and $\mathrm{MM}$ involved in design, writing, revising the manuscript, and approval of final version. SM, HN, SHH, AM, and SO involved in conception, design, data collection, literature review, writing the manuscript, and approval of final version. NA, MA, and FS involved in design, data collection, literature review, writing, revising the manuscript, and approval of final version of the manuscript. Additionally, all authors have read and approved the final manuscript.

\section{Funding}

This study was not funded.

\section{Availability of data and materials}

The datasets generated and analyzed during the current study are not publicly available due to our department privacy, but are available from the corresponding author on reasonable request.

\section{Ethics approval and consent to participate}

The study was approved by the Clinical Research Ethics Committee of Shiraz University of Medical Sciences (Ethic code: IR.SUMS.MED.REC.1398.338) in accordance with the code of ethics of the World Medical Association (Declaration of Helsinki) for experiments involving humans. A written informed consent was obtained from all patients before any intervention.

\section{Consent for publication}

"Not applicable", because this study is only a chart review and the manuscript does not contain data from any individual person.

\section{Competing interests}

The authors declare that they have no competing interests.

\section{Author details}

${ }^{1}$ Department of Radiation Oncology, Shiraz University of Medical Sciences, Shiraz, Iran. ${ }^{2}$ Shiraz Institute for Cancer Research, Medical School, Shiraz University of Medical Sciences, Shiraz, Iran. ${ }^{3}$ Breast Diseases Research Center, Shiraz University of Medical Sciences, Shiraz, Iran. ${ }^{4}$ Colorectal Research Center, Shiraz University of Medical Sciences, Shiraz 71936, Iran.

Received: 10 September 2019 Accepted: 13 September 2019

Published online: 22 October 2019

\section{References}

1. Biffi R, Botteri E, Cenciarelli S, Luca F, Pozzi S, Valvo M, et al. Impact on survival of the number of lymph nodes removed in patients with nodenegative gastric cancer submitted to extended lymph node dissection. Eur J Surg Oncol. 2011;37:305-11.

2. Marubini E, Bozzetti F, Miceli R, Bonfanti G, Gennari L. Lymphadenectomy in gastric cancer: prognostic role and therapeutic implications. Eur J Surg Oncol. 2002;28:406-12

3. Amin M, Edge S, Greene F, Byrd D, Brookland R, Washington M, et al. editors. AJCC cancer staging manual, Springer, 2017, pp 203-220.

4. Zhao J, Du F, Zhang Y, Kan J, Dong L, Shen G, et al. Impact on long-term survival of the number of lymph nodes resected in patients with pT1N0 gastric cancer after $\mathrm{R} 0$ resection: a multicenter study in China. Medicine (Baltimore). 2016;95:e4420.

5. Baxter NN, Tuttle TM. Inadequacy of lymph node staging in gastric cancer patients: a population-based study. Ann Surg Oncol. 2005;12:981-7.

6. Bouvier AM, Haas O, Piard F, Roignot P, Bonithon-Kopp C, Faivre J. How many nodes must be examined to accurately stage gastric carcinomas? Results from a population based study. Cancer. 2002;94:2862-6.

7. Chen S, Zhao B-W, Li Y-F, Feng X-Y, Sun X-W, Li W, et al. The prognostic value of harvested lymph nodes and the metastatic lymph node ratio for gastric cancer patients: results of a study of 1,101 patients. PLoS One. 2012; 7:e49424.

8. Huang C-M, Lin B-J, Lu H-S, Zhang X-F, Li P, Xie J-W. Effect of lymphadenectomy extent on advanced gastric cancer located in the cardia and fundus. World J Gastroenterol. 2008;14:4216-21.

9. Ichikura T, Ogawa T, Chochi K, Kawabata T, Sugasawa H, Mochizuki H. Minimum number of lymph nodes that should be examined for the International Union Against Cancer/American Joint Committee on Cancer TNM classification of gastric carcinoma. World J Surg. 2003;27:330-3.

10. Bruno L, Nesi G, Montinaro F, Carassale G, Boddi V, Bechi P, et al. Clinicopathologic characteristics and outcome indicators in node-negative gastric cancer. J Surg Oncol. 2000;74:30-2.

11. Giuliani A, Caporale A, Corona M, Di Bari M, Demoro M, Ricciardulli T, et al. Lymphadenectomy in gastric cancer: influence on prognosis of lymph node count. J Exp Clin Cancer Res. 2004;23:215-24.

12. Deng J, Liang $H$, Sun D, Pan $Y$, Zhang R, Wang B, et al. Outcome in relation to numbers of nodes harvested in lymph node-positive gastric cancer. Eur J Surg Oncol. 2009;35:814-9. 
13. Lee H, Yang HK, Kim W, Lee K, Choe K, Kim JP. Influence of the number of lymph nodes examined on staging of gastric cancer. Br J Surg. 2001;88: 1408-12.

14. Coburn NG, Swallow CJ, Kiss A, Law C. Significant regional variation in adequacy of lymph node assessment and survival in gastric cancer. Cancer. 2006;107:2143-51.

15. Schwarz RE, Smith DD. Clinical impact of lymphadenectomy extent in resectable gastric cancer of advanced stage. Ann Surg Oncol. 2007;14:317-28.

16. Shen Z, Ye Y, Xie Q, Liang B, Jiang K, Wang S. Effect of the number of lymph nodes harvested on the long-term survival of gastric cancer patients according to tumor stage and location: a 12-year study of 1,637 cases. Am J Surg. 2015;210:431-40 e433.

17. Smith DD, Schwarz RR, Schwarz RE. Impact of total lymph node count on staging and survival after gastrectomy for gastric cancer: data from a large US-population database. J Clin Oncol. 2005:23:7114-24.

18. Gholami S, Janson L, Worhunsky DJ, Tran TB, Squires MH, Jin LX, et al. Number of lymph nodes removed and survival after gastric cancer resection: an analysis from the US Gastric Cancer Collaborative. J Am Coll Surg. 2015;221:291-9.

19. Yu X, Hu F, Li C, Yao Q, Zhang H, Xue Y. Clinicopathologic characteristic and prognosis of proximal and distal gastric cancer. Onco Targets Ther. 2018:11:1037-44.

20. Karpeh MS, Leon L, Klimstra D, Brennan MF. Lymph node staging in gastric cancer: is location more important than number?: an analysis of 1,038 patients. Ann Surg. 2000;232:362-71.

21. Smith AJ, Law CH, Khalifa MA, Hsieh ET, Hanna SS, Wright FC, et al. Multimodal CME for surgeons and pathologists improves colon cancer staging. J Cancer Educ. 2003;18:81-5.

22. Huang C-M, Lin J-X, Zheng C-H, Li P, Xie J-W, Lin B-J. Effect of negative lymph node count on survival for gastric cancer after curative distal gastrectomy. Eur J Surg Oncol. 2011;37:481-7.

23. Hundahl SA, Phillips JL, Menck HR. The National Cancer Data Base report on poor survival of US gastric carcinoma patients treated with gastrectomy. Cancer. 2000;88:921-32.

24. Santoro R, Ettorre GM, Santoro E. Subtotal gastrectomy for gastric cancer. World J Gastroenterol. 2014;20:13667-80.

25. Datta J, Lewis RS, Mamtani R, Stripp D, Kelz RR, Drebin JA, et al. Implications of inadequate lymph node staging in resectable gastric cancer: a contemporary analysis using the National Cancer Data Base. Cancer. 2014; 120:2855-65.

\section{Publisher's Note}

Springer Nature remains neutral with regard to jurisdictional claims in published maps and institutional affiliations.

\section{Submit your manuscript to a SpringerOpen ${ }^{\circ}$ journal and benefit from:}

- Convenient online submission

- Rigorous peer review

- Open access: articles freely available online

- High visibility within the field

- Retaining the copyright to your article

Submit your next manuscript at $\boldsymbol{\nabla}$ springeropen.com 